\title{
Volatiles in Kimberlite: Volume Relationships and Implications for Conduit and Eruption Dynamics
}

\author{
J.K. Russell, T.M. Gordon and S. Moss \\ Earth \& Ocean Sciences, University of British Columbia, Vancouver, Canada V6T1Z4
}

\section{Introduction}

The unique aspect of kimberlite magmas is their potential for having high dissolved contents of primary volatiles (e.g., $\mathrm{H}_{2} \mathrm{O}+\mathrm{CO}_{2}>15$ wt. \%) coupled to a high ascent rate. The high ascent rates help couple the exsolved fluid to the magma as it rises to the point of eruption. During ascent the system evolves from a system featuring $30-40 \%$ suspended solids in a silicate melt to a system that is volumetrically dominated by the exsolved fluids (due to exsolution and expansion). Here, we explore the properties of the kimberlite melt phase and the associated $\mathrm{CO}_{2}-\mathrm{H}_{2} \mathrm{O}$ fluids, and relate these to kimberlite emplacement and eruption.

\section{Model Melt Compositions}

Chemical compositions of kimberlite melt are difficult to isolate because kimberlite is a hybrid rock representing a mixture of mantle and crustal xenoliths, macrocrysts, and subordinate amounts of cognate phenocrysts and groundmass material (Mitchell, 1986). Kimberlites are also enriched in volatiles, which can have post-eruption consequences. Even where kimberlite melt is quenched, post-eruption circulation of fluids can cause changes in bulk chemistry, replacement of primary minerals, and obliteration of primary textures and structures.

Sparks et al. (2006) compiled kimberlite melt compositions deriving from fine-grained aphanitic samples of kimberlite from the margins of dykes, melt compositions corrected for olivine accumulation, and reconstructed melt compositions from pyroclasts. There is a fair degree of agreement between estimates; on a normalized anhydrous basis they contain 30-36 wt. $\% \mathrm{SiO}_{2}, 25-36$ wt. $\% \mathrm{MgO}, 12-22$ wt. $\% \mathrm{CaO}, 8-$ 14 wt. $\% \mathrm{FeO}$, and 1-2.5 wt. \% $\mathrm{K}_{2} \mathrm{O}$. $\mathrm{CaO}$ shows the greatest variation. For our calculations we adopt the reconstructed compositions from Kopylova et al (2007) (Table 1). Kimberlite melts are expected to contain both $\mathrm{CO}_{2}$ and $\mathrm{H}_{2} \mathrm{O}$. Their exact amounts remain largely uncertain because kimberlite glass does not exist and kimberlite rocks are nearly always affected by late-stage fluid infiltration and reaction. We have added 5 wt. $\% \mathrm{H}_{2} \mathrm{O}$ and $10 \mathrm{wt} \% \mathrm{CO}_{2}$ to our base anhydrous composition which is equivalent to $\sim 10$ mol. \% of each volatile component (Table 1).

\section{Calculated Melt Properties}

The physical-chemical properties of kimberlite melt govern the transport and eruption behaviour of kimberlite magmas. Here we use computational models calibrated on experimental data for multicomponent melts to explore the physical properties of kimberlite.

\begin{tabular}{|c|c|c|c|c|}
\hline Oxide (Wt.\%) & Volatile-free & $\mathrm{H}_{2} \mathrm{O}(5 \mathrm{wt}$ & $\begin{array}{l}296 E-B \\
\%) C O,(10 \mathrm{Wt} \%)\end{array}$ & $\mathrm{H}_{2} \mathrm{O}+\mathrm{CO}_{2}$ \\
\hline $\mathrm{SiO}_{2}$ & 33.08 & 31.51 & 30.07 & 28.77 \\
\hline $\mathrm{TiO}_{2}$ & 1.71 & 1.63 & 1.56 & 1.49 \\
\hline $\mathrm{Al}_{2} \mathrm{O}_{3}$ & 2.15 & 2.05 & 1.95 & 1.87 \\
\hline $\mathrm{Cr}_{2} \mathrm{O}_{3}$ & 0.35 & 0.33 & 0.32 & 0.30 \\
\hline $\mathrm{FeO}(\mathrm{T})$ & 8.44 & 8.04 & 7.68 & 7.34 \\
\hline $\mathrm{MnO}$ & 0.21 & 0.20 & 0.19 & 0.18 \\
\hline $\mathrm{MgO}$ & 32.41 & 30.87 & 29.46 & 28.18 \\
\hline $\mathrm{CaO}$ & 18.73 & 17.83 & 17.02 & 16.28 \\
\hline $\mathrm{Na}_{2} \mathrm{O}$ & 0.15 & 0.14 & 0.14 & 0.13 \\
\hline $\mathrm{K}_{2} \mathrm{O}$ & 1.78 & 1.69 & 1.61 & 1.54 \\
\hline $\mathrm{P}_{2} \mathrm{O}_{5}$ & 0.99 & 0.95 & 0.90 & 0.86 \\
\hline $\mathrm{CO}_{2}$ & 0.00 & 0.00 & 9.09 & 8.70 \\
\hline $\mathrm{H}_{2} \mathrm{O}$ & 0.00 & 4.76 & 0.00 & 4.35 \\
\hline Total & 100.00 & 100.00 & 100.00 & 100.00 \\
\hline \multicolumn{5}{|c|}{ Computed Physical Properties $^{1,2}$} \\
\hline$\overline{\text { Density }(\mathrm{gm} / \mathrm{cm}}$ & 3.05 & 2.74 & 3.36 & 3.01 \\
\hline Volume $\left(\mathrm{cm}^{3} \mathrm{mo}\right.$ & 32.74 & 36.42 & 29.77 & 33.25 \\
\hline $\mathrm{Cp}\left(\mathrm{J} \mathrm{K}^{-1} \mathrm{~mol}^{-1}\right)$ & 171.7 & 175.6 & 156.1 & 160.3 \\
\hline A-VFT & -4.55 & -4.55 & -- & -. \\
\hline B-VFT & 4038 & 4713 & -- & -- \\
\hline C-VFT & 715 & 586 & -- & -- \\
\hline $\log \eta(\mathrm{Pas})$ & 0.44 & 0.48 & -- & -- \\
\hline $\mathrm{Tg}\left({ }^{\circ} \mathrm{C}\right)\left[10^{12} \mathrm{~Pa}\right.$ & 686 & 598 & 686 & 598 \\
\hline $\mathrm{M}$ & 65.0 & 50.6 & -- & -- \\
\hline
\end{tabular}

Density

Magma density controls the efficacy with which kimberlites ascend and their style of eruption. Figure 1 shows values of density for the main constituents in kimberlite magmas computed at $1250^{\circ} \mathrm{C}$ and crustal pressures; the bulk density of the magma is a linear combination of these constituent properties. Densities of kimberlite melts are computed with MELTS (Ghiorso \& Sack 1995; Fig. 1). Density decreases between 2\% (dry) and 12\% (volatile-rich) during ascent depending on volatile content. Anhydrous kimberlite has a density $\sim 3 \mathrm{~g} / \mathrm{cc}$ (Table 1); addition of $\mathrm{H}_{2} \mathrm{O}$ decreases density whilst dissolved $\mathrm{CO}_{2}$ causes an apparent increase in melt density (Note: relevant high-P compressibility data are sparse). Olivine macrocrysts have a density in excess $3.3 \mathrm{~g} / \mathrm{cc}$ and can comprise $\sim 40 \%$ of the kimberlite magma. The consequence is that, in the absence of an exsolved fluid phase, kimberlite magmas are likely to have densities in excess $3 \mathrm{~g} / \mathrm{cc}(\sim 3.12 \mathrm{~g} / \mathrm{cc})$.

Exsolution of a $\mathrm{CO}_{2}-\mathrm{H}_{2} \mathrm{O}$ fluid phase provides a logical and efficient means of reducing magma density and promoting the buoyancy critical for rapid ascent and eruption. Depending on fluid composition, density at the base of the crust varies between 1.1 and $0.7 \mathrm{~g} / \mathrm{cc}$. Magma density would be reduced to $\sim 2.7 \mathrm{~g} / \mathrm{cc}$ if exsolution produced 20 vol. \% fluid at lower crustal 
conditions. Even with no additional exsolution, the fluid phase will expand $\sim 60 \%$ once it reaches the upper crust reducing magma density to $<2.4 \mathrm{~g} / \mathrm{cc}$.

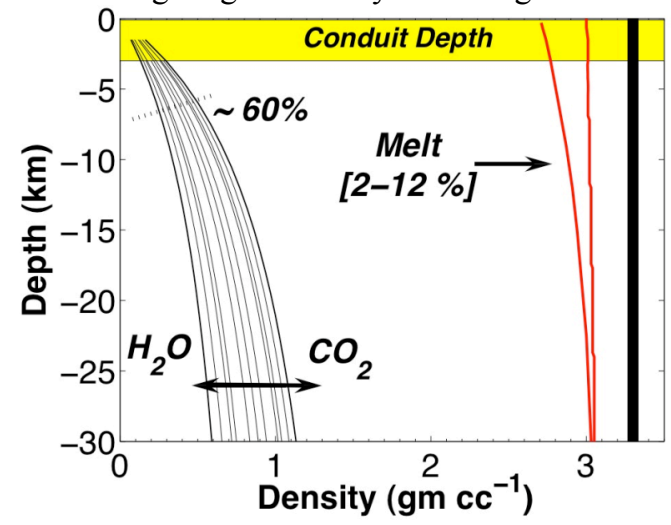

Fig. 1. Calculated densities pertinent to kimberlite ascent, including: kimberlite melt (red lines), olivine megacrysts (thick line), \& $\mathrm{CO}_{2}-\mathrm{H}_{2} \mathrm{O}$ fluids plotted as a function of depth.

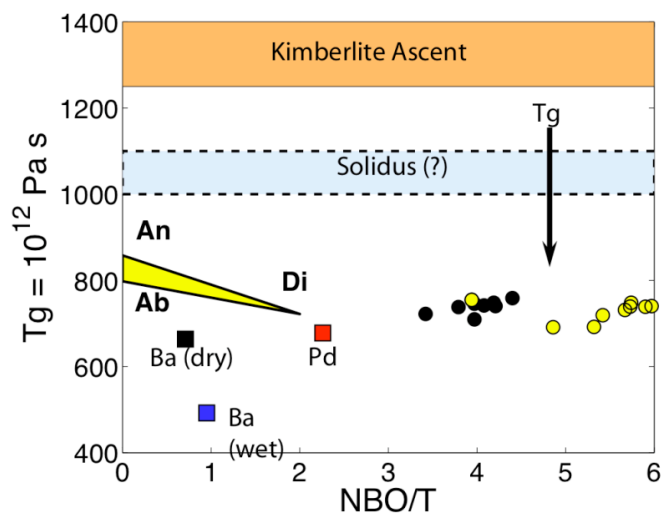

Fig. 2. Tg values for kimberlite, basalt (Ba), peridotite (Pd) and melts from system Di-Ab-An. Values are for dry (black) $\&$ volatile-rich (yellow) kimberlite (Sparks et al. 2006).

\section{Viscosity $(\eta)$ \& Glass Transition Temperature (Tg)}

The model of Giordano et al. (2008) allows us to compute transport properties of kimberlite melt (Table 1). The model does not account for dissolved $\mathrm{CO}_{2}$, however, recent work by Morizet et al. (2007) shows that, relative to $\mathrm{H}_{2} \mathrm{O}$, the effects of $\mathrm{CO}_{2}$ on melt transport properties are slight. Under normal conditions kimberlite melt will have values of $\eta<5 \mathrm{~Pa} \mathrm{~s}$.

Natural silicate glasses form under a variety of geological conditions and commonly form in silicic lava and in rapidly cooled mafic rocks. There are no occurrences of kimberlitic glass, which raises the question of whether glass forms in kimberlite eruption. Glass formation is a boundary between changing environmental states and the model for melt viscosity provides a means of predicting that boundary: $\mathrm{Tg}$ (the temperature where $\eta \sim 10^{12} \mathrm{~Pa} \mathrm{~s}$ ). Above Tg, rates of nucleation, crystallization and vesiculation are sufficiently fast to operate. Conversely, where the magma temperature intersects the melt's $\mathrm{Tg}$, glass forms and these magmatic processes effectively cease. Glass formation, therefore, depends on the gap between $\mathrm{T}_{\mathrm{Liq}}$ and $\mathrm{T}_{\mathrm{g}}$ and rates of melt cooling (Fig. 2).

The depression of $\mathrm{Tg}$ by increased $\mathrm{H}_{2} \mathrm{O}$ content provides a simple vehicle for production of glass during an eruption. Ascent and eruption causes volatile loss and a concomitant increase in $\mathrm{Tg}$, to the point that, Tg intersects magma temperature causing the melt to quench to glass. Kimberlite melts do not show the same depression in Tg (Fig. 2; Table 1) and thus lack this means of aiding glass formation. Furthermore, the $\Delta \mathrm{T}$ between kimberlite formation temperature and $\mathrm{Tg}$ is higher than in most magmas.

\section{Volatile Phase}

Ascent of kimberlite causes exsolution of a $\mathrm{CO}_{2}-\mathrm{H}_{2} \mathrm{O}$ fluid; the fluid composition depends on the total dissolved fluid content of the melt and the T-P ascent path (e.g., Holloway \& Blank 1994). Under conditions of equilibrium degassing (e.g., closed system), the original dissolved fluid content limits the range of fluid compositions produced during ascent. Under perfect fractional degassing (open system), increments of equilibrium fluid are released and "fractionated". Such situations arise when 2-phase flow (melt and gas) develops and the gas phase decouples from the host magma. Separated two-phase flow is likely to develop in kimberlite and allows for highly transient fluid compositions beginning with fluids extremely enriched in $\mathrm{CO}_{2}$, and ending with $\mathrm{H}_{2} \mathrm{O}$ dominated fluid. The physical properties and behaviour of the fluids during ascent are, thus, constantly changing in response to the evolving fluid composition.

\section{The $\mathrm{CO}_{2}-\mathrm{H}_{2} \mathrm{O}$ Equation of State}

The exsolved magmatic fluid is modelled as mixtures of $\mathrm{CO}_{2}$ and $\mathrm{H}_{2} \mathrm{O}$. No speciation calculations were attempted. The thermodynamic properties were retrieved using program REFPROP (Lemmon et al. 2007) that employs the GERG-2004 equation of state and mixing models (Kunz et al. 2007). The upper pressure limit for computations is restricted by the $\mathrm{CO}_{2}$ to pressures below $800 \mathrm{MPa}$. The lower pressure and temperature limits were chosen at $50 \mathrm{MPa}, 320{ }^{\circ} \mathrm{C}$ to ensure all compositions could be represented by a single fluid phase. Below we compute how the properties $(\mathrm{V}, \mathrm{H}, \mathrm{S})$ of the expanding fluid change as a function of ascent path. Subsequent plots of entropy and enthalpy and the isentropic and isenthalpic paths are based on "intrinsic" thermodynamic properties (Dodson, 1971). They do not include energy associated with motion or position in the gravitational field.

\section{Ascent Paths: Reversible vs. Irreversible}

The heat content of the magma is reduced by loss to wall rocks, by interactions with xenoliths, and by other endothermic reactions (e.g., vesiculation), or is increased by crystallization or viscous heating during flow (e.g., Spera 1984; Sparks et al 2006). However, as the magma decompresses, the fluid phase increases in mass and volume, and the thermal consequences of adiabatic expansion begin to dominate. There are twoend-members to adiabatic expansion processes (e.g., Spera 1984; Mastin \& Ghiorso 2003) in ascending magma (Fig. 3). The adiabatic expansion can proceed as a reversible isentropic process in which the expanding system does work on the environment. This process applies best to the final expansion of $\mathrm{CO}_{2}-\mathrm{H}_{2} \mathrm{O}$ 
fluids during eruption of kimberlite where the system vents at high velocity into the atmosphere (Mastin \& Ghiorso 2003, Sparks et al 2006). The work released to the environment is balanced by cooling of the system and entropy is conserved. Efficient cooling of the fluid phase can help cool and quench the melt to form glass.
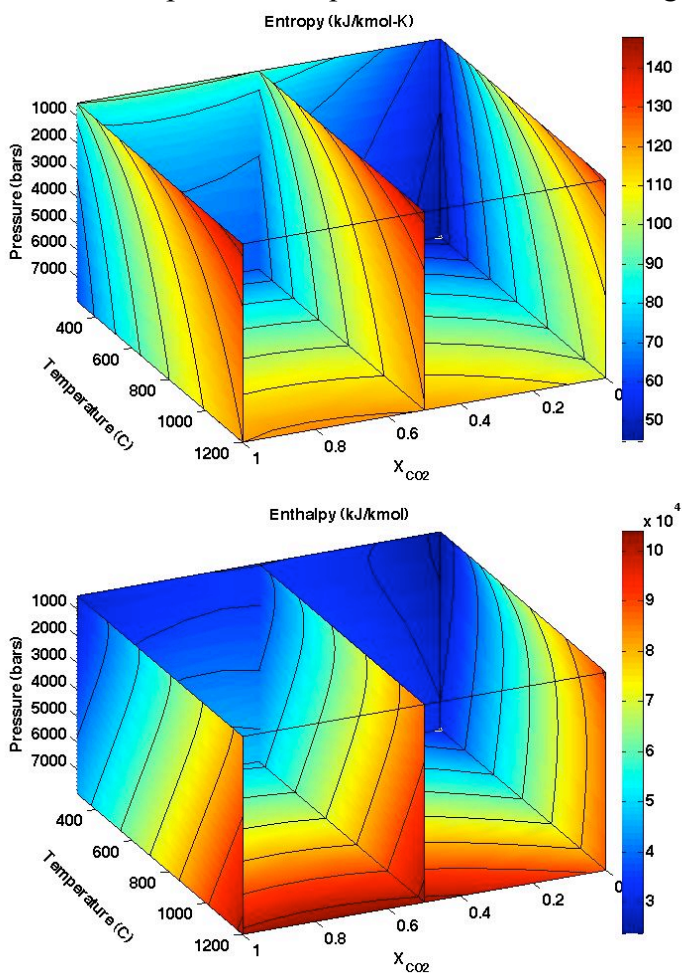

Fig. 3. Adiabatic expansion paths of $\mathrm{CO}_{2}-\mathrm{H}_{2} \mathrm{O}$ fluids as a function $\mathrm{P}, \& \mathrm{~T}$. Upper: reversible adiabatic expansion paths of fluid as iso-entropy contours; isentropic depressurization from depth can cause $400-500^{\circ} \mathrm{C}$ cooling of the fluid. Lower: irreversible isenthalpic expansion paths for $\mathrm{CO}_{2}-\mathrm{H}_{2} \mathrm{O}$ fluids. Isenthalpic expansive cooling of $\mathrm{H}_{2} \mathrm{O}$-fluids is slight until $<3$ $\mathrm{Kb} ; \mathrm{CO}_{2}$-rich fluids heat until during ascent until $<400$ bars.

Alternatively, during adiabatic isenthalpic expansion entropy is not. Isenthalpic expansion of a real fluid can cause either heating or cooling of the fluid depending on its composition (Fig. 3). This condition is best met during upward flow of kimberlite along established dykes where the magma loses negligible heat to the wall rocks. In this case, $\mathrm{CO}_{2}$ fluid-bearing kimberlite will heat during ascent until the point of eruption (Fig. 3) where adiabatic isentropic expansion into the atmosphere will cause substantial cooling of pyroclasts.

\section{Volcanological Implications}

High $\mathrm{CO}_{2}-\mathrm{H}_{2} \mathrm{O}$ contents promote explosive eruption of kimberlite characterized by high eruption velocities and high volume fluxes. There are several possible consequences of a collapsing volcanic plume at the end of the eruption. Depending on column height and the depth of the final fragmentation surface, the excavated portion conduit may be filled by a combination of: i) fragmented magma that did not erupt, ii) fall back material from the eruption column, and iii) material shed from inside flanks of the volcanic edifice. If the infill is above $\mathrm{Tg}$ (Fig. 4) we predict low porosity deposits due to welding or hot pressing; the loss of porosity and permeability ultimately facilitates deuteric alteration processes. Alternatively, we can envision a situation where highly efficient adiabatic cooling of the pyroclastic material resulting in conduits filled with cooler $(<\mathrm{Tg})$ deposits (Fig. 4). Porosity and permeability are preserved and passive-degassing proceeds along preferred pathways within the conduit. Alteration is expected to be patchy and to be localized around fluid escape channels. The nature of this late stage alteration is a direct indication of fluid composition in the waning stages of the eruption. In many cases these fluids are dominated by $\mathrm{H}_{2} \mathrm{O}$.

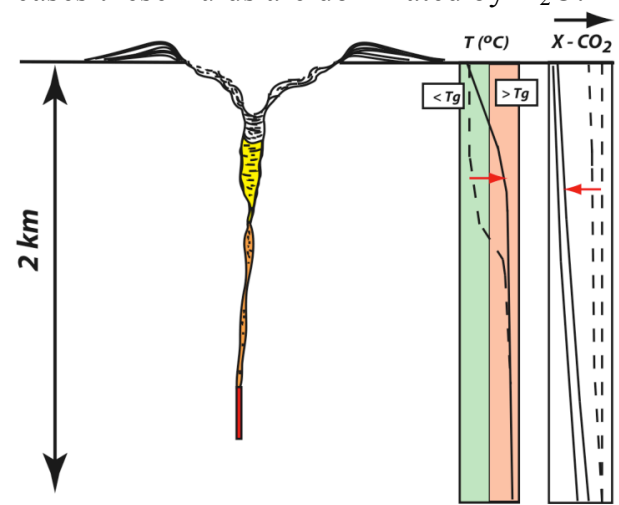

Fig 4. Post-eruption configuration of kimberlite pipe (left). Right side shows fluid composition and $\mathrm{T}\left({ }^{\circ} \mathrm{C}\right)$ in pipe-infill. Dashed lines are for small-volume, eruptions dominated by $\mathrm{CO}_{2}$ with high gas:melt ratios and resulting in cool conduit fill. Welding limited by the T-profile in conduit (see text). Solid lines denote large volume, eruptions featuring evolving fluid compositions. Final phase is $\mathrm{H}_{2} \mathrm{O}$-rich, has low gas:melt ratios and results in hot conduit fill (see text).

Acknowledgements: We thank Diavik Diamond Mines, Inc. (DDMI) and NSERC for financial and logistical support.

\section{References}

Dodson MH 1971. Isenthalpic flow, Joule-Kelvin coefficients \& mantle convection. Nature 234, 212.

Giordano D et al. 2008. Viscosity of magmatic Liquids: A model. Earth \& Planetary Science Letters.

Ghiorso MS \& Sack RO 1995. Chemical mass transfer in magmatic processes. Contributions Mineralogy \& Petrology 119, 197-212.

Holloway JR \& Blank JG 1994. Application of experimental results to C-O-H species in natural melts. in Volatiles in Magmas, MSA 20, 187-230.

Kopylova MG et al. 2007. Searching for parental kimberlite melt. Geochimica et Cosmochimica Acta, 71, 3616-3629.

Kunz O et al. 2007. The GERG-2004 wide-range reference equation of state for natural gases. GERG Technical Monograph 15. Fortschritt Berichte VDI, Reihe 6, 557.

Lemmon EW et al. 2007. Fluid Thermodynamic \& Transport Properties - REFPROP Version 8.0, NIST, Boulder, CO.

Mastin LG \& Ghiorso MS 2001. Adiabatic temperature changes of magma-gas mixtures during ascent and eruption. Contrib Mineral Petrol 141: 307-321.

Mitchell RH 1986. Kimberlites. Plenum Press, N.Y., 441p.

Morizet $\mathrm{Y}$ et al. 2007. Influence of $\mathrm{H}_{2} \mathrm{O} \& \mathrm{CO}_{2}$ on $\mathrm{Tg}$. European Journal Mineralogy 19, 657-669.

Sparks RSJ et al. 2006. Constraints on kimberlite volcanism. Journal Volcanology \& Geothermal Research 155, 18-48.

Spera, F.J. 1984. Carbon dioxide in petrogenesis.

Contributions Mineralogy \& Petrology, 88: 217-232. 